\title{
O PLANO ESTRATÉGICO EDUCATIVO MUNICIPAL ENQUANTO INSTRUMENTO DE REGULAÇÃO DA POLÍTICA EDUCATIVA LOCAL O caso de Alvito
}

\section{THE MUNICIPAL EDUCATIONAL STRATEGIC PLAN AS AN INSTRUMENT OF REGULATION OF LOCAL EDUCATION POLICY \\ The case of Alvito}

\author{
Filomena Machado \\ Instituto Politécnico de Beja \& Laboratório de Animação Territorial, IPBeja, Rua Pedro Soares, Campus do IPBeja, \\ Apartado 6155, 7800-295 Beja, Portugal. Email: filomena.machado@ipbeja.pt
}

\section{Sandra Saúde}

Instituto Politécnico de Beja; CICS.NOVA - Centro Interdisciplinar de Ciências Sociais \& Laboratório de Animação Territorial, IPBeja, Rua Pedro Soares, Campus do IPBeja, Apartado 6155, 7800-295 Beja, Portugal. Email: ssaude@ipbeja.pt

\section{Sandra Lopes}

Instituto Politécnico de Beja; CICS.NOVA - Centro Interdisciplinar de Ciências Sociais \& Laboratório de Animação Territorial, IPBeja, Rua Pedro Soares, Campus do IPBeja, Apartado 6155, 7800-295 Beja, Portugal. Email: slopes@ipbeja.pt

\begin{abstract}
Resumo: A participação dos municípios na educação é hoje uma realidade incontornável. O local transformou-se em espaço de construção de políticas educativas, onde autoridades locais, escolas e outros atores, partilham interesses e objetivos, fazendo emergir processos de "regulação sociocomunitária" (Barroso, 2013), aos quais são igualmente chamados a intervir elementos externos, portadores de conhecimento especializado, que possam garantir rigor e imparcialidade aos resultados alcançados. A partir da apresentação da metodologia adotada e dos resultados alcançados na conceção do Plano Estratégico Educativo do Município de Alvito (PEEMA), são demonstradas as potencialidades dos processos participados e comunitariamente partilhados enquanto método adequado para a construção de instrumentos de política pública local.
\end{abstract}

Palavras-chave: território educativo, projeto educativo municipal, planeamento estratégico, regulação da educação.

\begin{abstract}
The participation of municipalities in education is now an unavoidable reality. The local level has become a space for the construction of educational policies, where local authorities, schools and other actors share interests and objectives, causing processes of "socio-community regulation" (Barroso, 2013). Also called upon to intervene are other external elements, with specialized knowledge that can guarantee rigor and impartiality. Based on the presentation of the methodology and results achieved in the conception of the Strategic Educational Plan of the Municipality of Alvito (PEEMA), this paper shows the potentialities of participatory and community-shared processes as na appropriate method for the construction of local public policy instruments.
\end{abstract}

Keywords: educational territory, municipal educational project, strategic planning, education regulation. 


\section{Introdução}

No atual quadro legislativo, e na expetativa de aprovação definitiva de nova legislação que materialize o propósito assumido pelo atual governo (XXI Governo Constitucional) de aprofundar o processo de descentralização de competências para as autarquias, os municípios regem-se, ainda, pela Lei n..$^{\circ}$ 75/2013, de 12 de setembro, regulamentada pelo Decreto-lei n. ${ }^{\circ}$ 30/2015, de 12 de fevereiro. No que se refere à educação básica e secundária, este decreto, no seu artigo $8 .^{\circ}$, descreve as competências delegáveis nos órgãos dos municípios e das entidades intermunicipais em cinco domínios: gestão escolar e práticas educativas; gestão curricular e pedagógica; gestão de recursos humanos; gestão orçamental e de recursos financeiros; gestão de equipamentos e infraestruturas do ensino básico e secundário. No âmbito do primeiro domínio é assumida a conceção do Plano Estratégico Educativo Municipal (PEEM) da rede escolar e da oferta educativa e formativa como uma das "novas" possibilidades de planeamento educativo à escala local que as autarquias devem dinamizar. Desde 2013 e, particularmente, desde 2015 são alguns os municípios que decidiram avançar para o desenvolvimento de PEEM, sustentados, maioritariamente, na celebração de contratos interadministrativos entre governo, município e escolas.

Apesar de não ter assinado um contrato interadministrativo, a Câmara Municipal de Alvito tomou a iniciativa de desencadear, em 2015, o processo de elaboração de um Plano Estratégico Educativo para o Município de Alvito (PEEMA), para o horizonte temporal de 2017 a 2021, onde se inclui a atualização da Carta Educativa. A iniciativa é justificada pela necessidade de ter um instrumento de política educativa local atualizado e construído a partir da participação de todos os atores envolvidos na dinâmica educativa municipal e de toda a comunidade. Pretende-se que sejam os destinatários e os atores os principais protagonistas e fontes do processo de definição de metas e ações a concretizar até 2021, assumindo a educação com um dos vetores estratégicos e fundamentais do desenvolvimento do concelho. Ao assumir o Lema: para um futuro melhor! É assumido para o PEEMA a aposta em consolidar Alvito como um “(...) município que se assume como um espaço educativo dinâmico, intercomunicante, promotor constante da inovação e da identidade sociocultural, sustentado nas estruturas educativas existentes e complementado pela aposta no enriquecimento das competências sociais e comunitárias de todos os munícipes." (Saúde, Lopes e Machado, 2017, p. 25).

Tendo por base a experiência desenvolvida de consultoria prestada à Câmara Municipal de Alvito ao longo de todo o processo de revisão da Carta Educativa e de conceção do PEEMA (que decorre desde setembro de 2015), ancorada nos 
pressupostos teóricos e metodológicos da sociologia da ação pública, pretende-se com o presente artigo refletir sobre a importância dos processos partilhados no planeamento da ação política local, bem como, testemunhar a dinâmica de mobilização dos atores locais, conducente à operacionalização de uma estratégia de ação coletiva.

\section{O Plano Estratégico Educativo Municipal de Alvito (PEEMA) como instrumento de ação pública}

A participação dos municípios hoje na educação é uma realidade incontornável, apesar do lento processo de descentralização de competências do Estado Central para o poder local, demonstrados e refletidos, entre outros, por Fernandes (1994) e Formosinho e Machado (2013). Apesar do papel excessivamente centralizador e uniformizador assumido pelo Estado ao nível da educação (Azevedo, 2015), a verdade é que, nas últimas décadas, o enquadramento legislativo tem permitido, e incentivado, a assunção de novas responsabilidades por parte das autarquias, de que são exemplo a obrigatoriedade de elaboração das Cartas Educativas e de criação dos Conselhos Municipais de Educação, bem como, a gestão de mais áreas no domínio da ação social escolar, das atividades extracurriculares, da manutenção das infraestruturas e/ou da gestão de pessoal não docente, particularmente, ao nível do $1 .^{\circ}$ ciclo. São disso, também, exemplo as iniciativas legislativas que possibilitaram os contratos de execução e os contratos interadministrativos onde se estipulam regras de contratualização envolvendo diferentes atores, como sejam o Ministério da Educação, o município e as escolas.

Apesar de lentas e muito espaçadas no tempo, as iniciativas legislativas têm vindo a permitir, no entanto, segundo Cordeiro, Alcoforado e Ferreira (2014) o aprofundamento da territorialização das políticas de educação, bem como, da participação dos municípios neste domínio. Para Barroso (2013) é, também, evidente que o "local" tem emergido como lugar privilegiado para a construção de novos referentes - estudos, planos, investigações, que atestam a importância e a influência que tem vindo a ser dada aos atores locais, no domínio da educação. Nesse mesmo sentido vai o enquadramento legislativo (Lei n. ${ }^{\circ}$ 75/2013, de 12 de setembro) que assume o Plano Estratégico Educativo Municipal como um instrumento importante na definição das políticas municipais, e até supramunicipais, no domínio da educação.

Partindo do entendimento da educação como um assunto que a todos - família, escola, cidadãos, associaç̃oes, poder local - diz respeito, a construção de um Plano Estratégico Educativo Municipal deve ser operacionalizada "num determinado território, com a participação, o envolvimento e a implicação de atores bem concretos e com uma visão e um sentido estratégico bem definidos" (Almeida, 2014, p. 25). Tal 
entendimento implica que se considere a escola, não como o "centro da coletividade", mas apenas "uma entre as muitas instituições da sociedade que promovem a educação (...) através de um aproveitamento das potencialidades culturais e educativas que existem na sociedade e de uma responsabilização do conjunto das entidades públicas e privadas" (Nóvoa, 2009, p. 9).

O caso concreto da construção do Plano Estratégico Educativo Municipal de Alvito (PEEMA) assume-se neste contexto como um objeto pertinente de análise do domínio da sociologia da ação pública, quer pela pertinência e atualidade do tema, quer por, e principalmente, ser um caso exemplificativo de como por iniciativa municipal foram mobilizados todos os atores locais para a construção partilhada de um instrumento de política municipal que visa melhor resolver localmente os problemas que a ação centralizadora do Estado não alcança.

Ao procurarmos analisar a construção do PEEMA enquanto processo de ação pública pretende-se compreender melhor os novos modos de regulação das políticas educativas a nível local, pondo em evidência as relações entre os atores e o modo como se combinam recursos e se definem prioridades para a ação local. Tratando-se de um processo de iniciativa comunitária, de livre adesão e associação e, portanto, não imposto nem formalmente regulamentado, torna-se pertinente analisar as suas potencialidades enquanto processo de "regulação sociocomunitária" (Barroso, 2013) ou "regulação voluntária descentralizada" (Justino, 2012).

\section{Objetivos e metodologia de construção do PEEMA}

Assumindo-se como uma resposta integrada às necessidades da comunidade, a elaboração do PEEMA visou operacionalizar a vontade do município em qualificar e melhorar a educação e a formação de todos os munícipes, em todas as fases e contextos de vida, através da otimização dos recursos disponíveis. Para tal, construiu-se um quadro metodológico assente em três conceitos fundamentais: por um lado, o conceito de território educativo, considerado enquanto espaço/tempo organizado para a definição, e realização, de um projeto educativo local que se assume como um contributo para o processo de desenvolvimento local (Pinhal, 2014). Adicionalmente, é um instrumento que visa contribuir e é veículo de um processo de territorialização, ou seja, de "apropriação", desejada pela comunidade de Alvito ao nível da gestão da dinâmica educativa (Barroso, 2013). Por último, o PEEMA configura-se como um projeto estratégico educativo municipal, que se traduzirá num contrato educativo, celebrado com toda a comunidade local, tendo por base o reforço do espaço público da educação (Nóvoa, 2009).

O PEEMA visou os seguintes propósitos: 
1. Definir a missão e a visão desejadas para o Território Educativo de Alvito para os próximos quatro (4) anos;

2. Facilitar e promover o diálogo e a participação da comunidade de Alvito, nos próximos (4) anos, na concretização de ações estratégicas tendo em vista a melhoria da dinâmica educativa;

3. Potenciar a melhoria dos espaços de trabalho e das ofertas educativas, formais e não formais, existentes em Alvito;

4. Corresponsabilizar os diferentes atores com ação educativa, em Alvito, na execução de um plano de ação de melhoria estratégica em termos socioeducativos;

5. Contribuir para a construção da política educativa local.

Destaca-se como pressuposto base do PEEMA a otimização dos recursos existentes, no sentido de serem eliminadas redundâncias e evitadas concorrências entre interlocutores. Foi assumido por todos os intervenientes no PEEMA que persistem obstáculos à ação coletiva, tendo sido a construção partilhada do PEEMA considerada uma excelente oportunidade para a promoção da concertação coletiva.

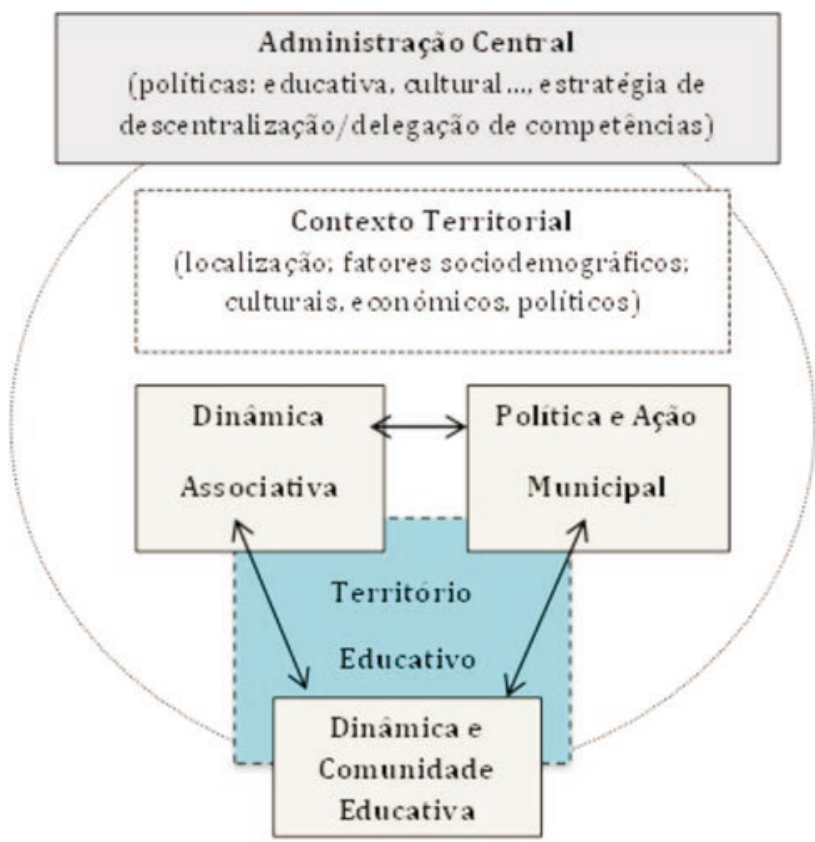

Figura 1 Modelo de Análise

Fonte: Elaboração própria. 


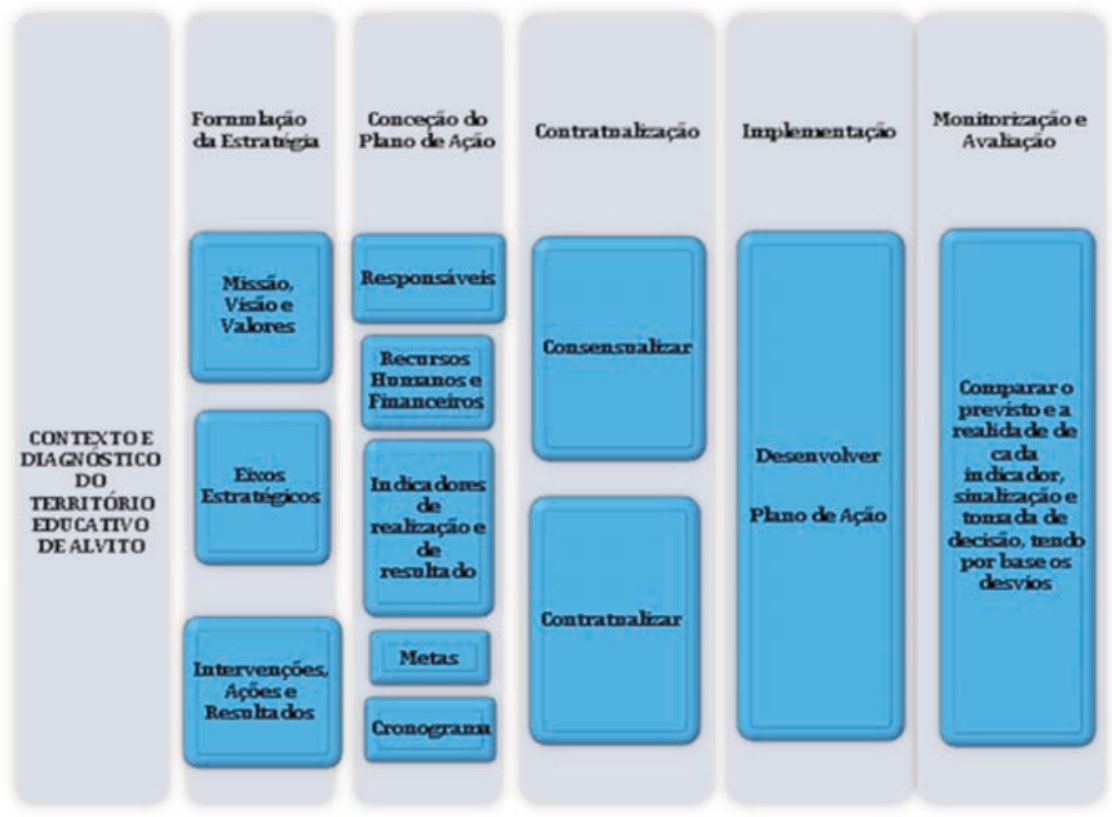

Figura 2 Fases do PEEMA

Fonte: Elaboração própria.

A construção do PEEMA desenvolveu-se num formato de "metodologia participativa de projeto", de pesquisa-ação, de cariz eminentemente qualitativo, visando caracterizar os contextos sociais e compreender a ação dos agentes, desde a descrição da realidade passada e atual, às dinâmicas e processos, à representação/expectativas dos agentes face ao contexto futuro que será portador de mudança (Guerra, 2000). A construção de um processo de planeamento participado, constituiu a orientação metodológica fundamental, já que se procurou dinamizar um processo de mudança coletivo baseado na construção partilhada de um plano de ação.

O modelo conceptual da relação entre agentes e campos de ação evidencia esse processo partilhado, assumido a nível político e inscrito no modelo de construção efetivo do PEEMA (figura 1).

Operacionalmente, a construção do PEEMA desenvolveu-se segundo 6 fases, esquematicamente apresentadas a seguir (figura 2).

Assumiu-se o planeamento participado como orientação metodológica fundamental dado o objetivo final de construção de um processo de mudança coletivo baseado na construção partilhada e portador de inovação, sendo decomposto nas seguintes fases: 
Fase 1: apresentação pública dos pressupostos que presidiram à conceção do Plano Estratégico, onde foram refletidas e justificadas as necessidade, as preocupações e as motivações que presidiram à sua construção. Tratou-se de um momento de divulgação e, também, de partilha dos fundamentos políticos e os justificativos práticos inerentes à construção do PEEMA. Sendo um projeto de iniciativa municipal, previamente aprovada pelos respetivos órgãos deliberativos e consultivos, importou dar a conhecer a todos os atores com intervenção no Território Educativo de Alvito, as características do processo e, sobretudo, a metodologia a aplicar que passaria pela realização de vários fóruns comunitários com objetivos diferenciados, entre outros momentos de auscultação direta;

Fase 2: caracterização do Território Educativo de Alvito com realização de visitas e reuniões para recolha de informações e auscultação de opiniões/expectativas, tendo em vista a recolha de informação pertinente para o processo de diagnóstico, bem como, a construção partilhada de um levantamento dos principais pontos fortes/fracos e oportunidades/ameaças do município.

Nesta fase procedeu-se a uma caracterização aprofundada do território e da sua população, no que diz respeito aos fatores geográficos, sociodemográficos, culturais, económicos. Para tal, recorreu-se a técnicas de análise documental que englobaram, num primeiro momento, a consulta e recolha de um conjunto vasto de informação estatística oficial, disponibilizada pelo Instituto Nacional de Estatística (INE). Em paralelo, recorreu-se a informação retirada de documentos produzidos pela Câmara Municipal ou por entidades parceiras (por ex. Plano Diretor Municipal, Plano de Desenvolvimento Estratégico, Carta Social de Alvito), bem como a diversa documentação interna solicitada à equipa técnica municipal. Foram também utilizados documentos oficiais enquadradores da ação política de desenvolvimento nacional e regional, nomeadamente os relativos à estratégia de desenvolvimento regional para o Horizonte 2020. Para dar corpo à caracterização sociodemográfica foram construídos indicadores de acordo com as necessidades do processo e com o detalhe geográfico pretendido. A preocupação foi sempre a de compreender a dinâmica (situacional e tendencial), numa base comparativa, recorrendo a dados organizados numa série temporal significativa, e enquadrar a realidade municipal no país e na região em que se integra e com a qual se relaciona prioritariamente (NUTS III Baixo Alentejo e NUTS III Alentejo Central). A caracterização sociodemográfica constituiu uma base importante para a elaboração dos cenários prospetivos da população residente e permitiu enquadrar as estimativas de evolução da população escolar.

Para a caracterização aprofundada da ação municipal na área socioeducativa procurou-se informação sobre os projetos desenvolvidos pela autarquia e as ações 
com vista ao cumprimento das competências que lhe foram delegadas, assim como, conhecer as dinâmicas associadas aos equipamentos e aos gabinetes municipais direta ou indiretamente, envolvidos no setor educativo. Numa primeira fase recorreu-se à documentação oficial - recolha de informação sobre os projetos: sobre a ação; caracterização dos equipamentos, atribuições; planos de atividades, população alvo (recorreu-se novamente a uma ficha de recolha de informação). Foram feitas entrevistas com guião semi-diretivo, em formato individualizado aos responsáveis pelos seguintes setores: coordenador dos serviços de ação cultural, social e educativa; técnicos superiores de ação educativa e social; responsáveis pela Biblioteca (principal e polo); responsáveis pela Universidade Sénior. Foram também realizadas visitas a todos os espaços e equipamentos municipais com um guião de recolha de informação construído para o efeito. A informação recolhida através de observação direta e indireta foi alvo de análise de conteúdo categorial temática.

No que respeita à caracterização e compreensão da dinâmica dos intervenientes no denominado território educativo, entendido como espaço de ação público e partilhado, foram feitas visitas, bem como, realizadas entrevistas aos responsáveis/dirigentes das respetivas associações segundo o formato de entrevista coletiva (focus group). Esta modalidade de construção foi considerada adequada dado que se procurou, por um lado, fazer um levantamento exploratório, compreender o grau de envolvimento dos observados, ações e expectativas ao nível das suas práticas e ações, e, por outro lado, descortinar consensos e tensões entre os vários atores locais com intervenção socioeducativa, bem como compreender as prioridades de ação educativa municipal, problemas a ultrapassar e desejos coletivos a alcançar. Por último, para a caraterização detalhada da rede educativa e das problemáticas associadas aos contextos formativos - Agrupamento de Escolas de Alvito e Escola Profissional de Alvito, foram utilizadas fontes documentais (oficiais da escola e do INE), projetos educativos de escola, descritivos sobre os projetos realizados nas escolas; entrevistas feitas a elementos-chave; reuniões com elementos da direção; visita às escolas (salas de aulas e outros espaços); reuniões com professores; alunos e representante da associação de pais.

O resultado da metodologia descrita permitiu a conceção de um diagnóstico detalhado da dinâmica socioeducativa de Alvito. Este mesmo diagnóstico foi devolvido à comunidade e aos diferentes atores através da realização de dois (2) fóruns comunitários, com o propósito de garantir a reflexão partilhada da caracterização feita e existente, bem como, a consensualização dos vetores estratégicos a trabalhar no PEEMA. O diagnóstico efetuado está plasmado no documento Carta Educativa do Município de Alvito. 
Fase 3: identificação do lema, da visão e dos eixos estratégicos-chave para a evolução do Território Educativo de Alvito até 2021. A identificação está consubstanciada no processo de diagnóstico desenvolvido na fase 2 , bem como, nas reuniões de trabalho desenvolvidas com os atores locais, e, também, com a autarquia e respetivos membros da equipa. O momento de apresentação e discussão pública do diagnóstico em sede da assembleia municipal foi também estruturante para esta fase. Nesse momento, para além dos seus membros também se envolveram na reflexão um grupo muito expressivo de munícipes;

Fase 4: apresentação e discussão pública com os atores do Território Educativo de Alvito, da matriz de eixos, intervenções e ações que corporizam o Plano de Ação proposto até 2021. Este processo de construção durou cerca de 10 meses, entre setembro de 2016 e junho de 2017, o que conduziu ao reajustamento do quadro temporal inicialmente equacionado: do período inicial previsto de 2016 para 2020 para a execução do PEEMA, passou-se para o quadriénio de 2017 a 2021. Realizaram-se para o efeito vários fóruns que serviram para estabilizar a visão desejada para Alvito e, sobretudo, para discutir e rever de forma partilhada com os diversos interlocutores locais e regionais os objetivos, os indicadores de resultado, de realização, de impacto, as metas e o orçamento previsto para cada uma das ações constantes no Plano de Ação. Operacionalizou-se por esta via a assunção básica deste processo de que o PEEMA deve ser a tradução prática da capacidade, dos recursos e dos interesses conjugados dos atores locais para a mudança efetiva. Durante este período de 10 meses realizaram-se fóruns de trabalho conjunto, que tiveram como objetivo dinamizar a construção partilhada de cada plano de ação ajustado a cada intervenção. Os momentos bastante participados o que permitiu ainda aprofundar mais a relação comunitária com o instrumento de política pública local em construção;

Fase 5: para cada intervenção constante no Plano de Ação foram assumidas atividades a desenvolver pelas equipas responsáveis. O Plano de Ação do PEEMA corporiza complementarmente uma estratégia de monitorização e de avaliação que acompanhará todo o processo de implementação e desenvolvimento. O PEEMA ficou terminado após a apresentação e discussão pública da proposta global e, finalmente, pelo ato público de contratualização com os diversos interlocutores com responsabilidades na sua concretização efetiva, desde o município até às associações culturais e desportivas existentes, passando pelo agrupamento de escolas, escola profissional e empresas, entre outros.

A construção metodológica do PEEMA esteve estruturalmente sustentada na participação ativa e transversal, dos múltiplos atores-chave locais e regionais. 
Utilizaram-se para o efeito, e complementarmente aos guiões de observação direta (para as visitas) e aos guiões das entrevistas, um diário de campo onde foram registados todos os momentos importantes das interações realizadas. Durante os fóruns comunitários fez-se recurso ao registo áudio e vídeo dos momentos, ${ }^{1}$ o que permitiu, com recurso à análise de conteúdo, extrair as principais unidades de registo significantes para a gestão e avaliação do processo de construção do PEEMA.

Os processos de reflexão partilhada foram desde o início, e serão até ao fim do processo, fulcrais para a definição da matriz de responsabilidades assumidas e a assumir desde a fase de conceção do Plano de Ação até às que se seguirão na fase de implementação, de monitorização e de avaliação do PEEMA. Preconiza-se, como princípio fundador e transversal deste projeto, um Plano Estratégico realista, vivo e mobilizador da mudança efetiva.

\section{O PEEMA - Contexto de ação e elementos do diagnóstico local ${ }^{2}$}

O município de Alvito pertence à NUT III Baixo Alentejo, e integra duas freguesias, Alvito e Vila Nova da Baronia, muito semelhantes, quer em população, quer em área ocupada. Território duplamente envelhecido, pouco populoso (2.504 habitantes, 2011) e de baixa densidade $\left(9 \mathrm{hab} / \mathrm{Km}^{2}\right)$, que beneficia da proximidade às cidades de Évora e Beja e das ligações ferroviárias ali existentes.

Alvito é conhecido pelos elementos patrimoniais construídos, bem como pelas festividades e gastronomia local. Existe oferta educativa local de nível pré-escolar, de nível básico regular e vocacional, bem como de nível secundário profissional. Desde 2001 que o município regista importantes alterações em diversos parâmetros educativos: diminuição da taxa de analfabetismo, aumento geral dos níveis de qualificação da população residente, bem como uma melhoria gradual da rede de equipamentos educativos e formativos.

A oferta de ensino regular é garantida pelo Agrupamento Vertical de Escolas de Alvito (edifício construído em 2011-12, resultante da aprovação da primeira carta educativa de Alvito, datada de 2006). O ensino vocacional e profissional é garantido pela Escola Profissional de Alvito, cuja oferta está especialmente direcionada para a hotelaria e restauração. A população adulta conta com ofertas pontuais asseguradas por operadores privados e pelo IEFP, contudo não existe um espaço/edifício reservado para esta função. A população com 50 e mais anos conta com um programa anual regular de oferta formativa gratuita - Universidade Sénior, projeto recente (2015) de iniciativa camarária. Em termos sociais, regista-se boa oferta de serviços de apoio aos idosos, mas a inexistência de serviços de apoio a crianças com menos de 3 anos. Nos últimos 10 anos, o concelho registou uma média anual 


\begin{tabular}{lccccc}
\hline & Pré-escolar & 1. ${ }^{\circ}$ CEB & 2. ${ }^{\circ}$ CEB & 3. ${ }^{\circ}$ CEB & $\begin{array}{c}\text { Ens. Sec. } \\
\text { Profissional }\end{array}$ \\
\hline Alunos inscritos 2015/16 & 49 & 70 & 44 & 104 & 213 \\
Alunos estimados 2019/20 & 51 & 78 & 30 & 109 & 230 \\
\hline
\end{tabular}

Fonte: Saúde, Lopes, e Machado (2016).

de frequência escolar de 489 alunos, do pré-escolar ao ensino secundário profissional. Destes, 250 alunos residem e estudam no concelho e os restantes 239 alunos são oriundos dos concelhos vizinhos e estudam na Escola Profissional de Alvito. Ou seja, estamos perante um município, que apesar de ser um dos mais pequenos e menos populosos do Baixo Alentejo, revela uma capacidade de atração educativa elevada ao nível da oferta de ensino vocacional e secundário, já que $49 \%$ da população estudantil, a frequentar a escola profissional do Alvito reside fora do concelho.

As estimativas de evolução da população escolar, 2015/16 a 2019/20, apresentam-se otimistas para o último ano do momento prospetivo, apesar de existirem algumas oscilações ao longo da série considerada. Esta situação decorre de vários aspetos que possuem diferentes impactos num quantitativo populacional muito pequeno, nomeadamente, salientamos como exemplos mais significativos: oscilações ao nível dos nascimentos observados; diminuição das taxas de retenção da população escolar em alguns anos e níveis de escolaridade. ${ }^{3}$ Esta situação não é idêntica em todos os ciclos de ensino e explica as diferenças observadas ao nível do 1. ${ }^{\circ}$ ciclo, 2. ${ }^{\circ}$ ciclo e $3 .^{\circ}$ ciclo do Ensino Básico. ${ }^{4}$ No caso do ensino secundário os cenários têm em conta a hipótese do número de alunos do ensino secundário profissional poder crescer, em termos médios, de acordo com o estimado pela DGEEC/MEC para a população escolar do ensino profissional residente nas NUTS III - correspondente a $2 \% .^{5}$

É num contexto de expectável estabilidade educativa que emerge a mobilização dos atores locais para a construção e implementação do PEEMA, a partir da iniciativa da Câmara Municipal.

\section{Resultados}

No PEEMA, a vigorar de 2017 a 2021, assume-se como desígnio: consolidar Alvito como um Município Educador e com uma dinâmica e uma ALMA MAIOR, que sua geografia, reconhecido, por todos, como valorizador da qualificação da sua população e dos seus recursos (Saúde, Lopes e Machado, 2017). 
Num Plano de Ação estruturado em 5 eixos estratégicos é assumida a aposta na interligação profícua entre educação, economia, rejuvenescimento demográfico e revitalização cultural. A abordagem holística ao conceito de educação está bem visível no PEEMA, onde se pretende estimular a construção partilhada de projetos, e iniciativas, que contribuam para a formação integral de todos/as (jovens e adultos), bem como para a qualificação das estruturas e agentes locais. Os eixos apresentam-se como multidimensionais, pois entrecruzam-se com outros campos e dimensões da vida comunitária. Assim:

- O Eixo 1 - Consolidar a qualidade e o reconhecimento dos processos formativos, integra intervenções orientadas para a qualificação dos espaços educativos e para a aposta na marca Alvito como Município Educador;

- O Eixo 2 - Apostar num ecossistema acolhedor, inovador e impulsionador do empreendedorismo, cria condições para apostar no empreendedorismo com diferentes públicos e em diversos contextos;

- O Eixo 3 - Melhorar os níveis de qualificação e de sucesso educativo, orienta-se para a melhoria de resultados educativos;

- O Eixo 4 - Enriquecer a cidadania participativa, solidária e o sentimento de pertença, alberga as intervenções destinadas ao reforço da dinâmica associativa e de voluntariado;

- O Eixo 5 - Reforçar a aposta na valorização dos recursos endógenos para a diferenciação educativa, cultural e económica, visa apostar e consolidar projetos distintivos ancorados nos elementos patrimoniais locais.

Os 5 eixos estratégicos enquadram um Plano de Ação com 13 intervenções e 15 ações, devidamente estruturadas, com inclusão de indicadores de realização, de resultado e metas, bem como um cronograma orientador da implementação. Para cada ação foram definidos objetivos, metas, indicadores de realização, de resultado e de impacto, bem como, os recursos financeiros e o respetivo cronograma de execução, o que tornou necessário entendimentos e a partilha de compromissos. Este modus operandi corresponsabiliza todos, desde a conceção à execução. A título de exemplo destacam-se duas ações, em que se aposta fortemente na diferenciação educativa local, bem como se indicam os respetivos objetivos na tabela 2.

Nos casos identificados, a identificação dos objetivos e, do consequente plano de ação, resultou do contributo específico da equipa responsável. A incorporação do objetivo de Alvito passar a integrar a rede portuguesa de cidades educadoras traduz a formalização de algo já desejado, e falado, há algum tempo pelos principais atores educativos, como são o Agrupamento de Escolas e a Escola Profissional de 
Tabela 2 Exemplos de ações estratégicas do PEEMA

\begin{tabular}{ll}
\hline Ação Estratégica & Objetivos \\
\hline & - Promover Alvito como município educador sustentável; \\
& - Melhorar o acesso à informação e aos mecanismos de \\
comunicação na área da educação, através da criação do portal & $\begin{array}{l}\text { Alvito Educador onde se divulgam e armazenam todas as } \\
\text { informações de âmbito educativo; }\end{array}$ \\
& - Aderir à rede portuguesa das cidades educadoras. \\
& - Promover a sustentabilidade da dinâmica associativa \\
municipal; & $\begin{array}{l}\text { - Promover a realização de projetos comuns rentabilizando os } \\
\text { contextos de aprendizagem, formais e não formais; } \\
\text { do município }\end{array}$ \\
- Contribuir para a valorização do património sociocultural e da \\
dinâmica desportiva de Alvito.
\end{tabular}

Fonte: elaboração própria.

Alvito. Com a reflexão feita durante a construção do PEEMA passou de desejo à definição de meta a concretizar a curto prazo, sendo que para todos ficou claro que para ser concretizável têm que melhorar o trabalho em parceria, exponenciando as potencialidades das diversas associações e entidades existentes, nomeadamente as que projetam o nome de Alvito para além dos seus limites geográficos, como são os casos, entre outras, da Associação Estudos Gerais liderada por Jorge Gaspar ou da empresa SPIRA- Revitalização Patrimonial, Lda.

No que respeita à dinâmica associativa, a reflexão permitiu fazer emergir "alguma conflitualidade latente" dada a diversidade e a quantidade de associações culturais e desportivas que "disputam" o mesmo tipo de público, principalmente o mais jovem, após o horário escolar. Foi na construção desta ação que mais se revelou útil, na opinião de todos, o processo de reflexão partilhado, na medida em que, segundo os próprios, apesar de se conhecerem muito bem, a verdade é que a planificação em conjunto nunca tinha sido testada. Foram descobertas áreas de atuação passíveis de serem complementadas entre associações e, sobretudo, assumiu-se como meta fundamental a construção mensal de uma agenda cultural que não resulte do somatório habitual de atividades apresentadas por cada um, mas, sim, de organizações partilhadas e articuladas.

Para além da perspetiva de mudança que lhe está associada, o PEEMA foi/tem sido essencialmente "utilizado" como um instrumento de promoção de corresponsabilização local. A realização dos fóruns comunitários com os diversos agentes socioeducativos, internos e externos, ao município de Alvito, foi uma 
aposta estratégica bem-sucedida com resultados positivos ao nível da concertação das várias intervenções do plano de ação. Foram realizados 6 fóruns, com níveis de participação que oscilaram entre os $85 \%$ e os $98 \%$ das entidades/interlocutores convidadas. Foi possível contar com a participação de cerca de 35 entidades, entre as quais se contam, as escolas, as autarquias, associações de âmbito cultural, desportivo, recreativo e de desenvolvimento local, equipas locais/regionais de organismos do Estado, IPSS, pessoas-recurso, equipas de projeto e empresas.

Os fóruns constituíram-se como momentos importantes de partilha de informação, de expressão de interesses, mas, também, de tensões e conflitos, que nos ajudam a compreender as potencialidades e os constrangimentos da dinâmica socioeducativa local, para a qual todos os esforços e resultados do PEEMA devem convergir. Na fase de diagnóstico, que culminou com a construção partilhada de uma análise SWOT e reflexão sobre o cenário demográfico prospetivado para Alvito até 2020, a discussão ajudou a identificar de forma mais partilhada, realista e antecipatória, os problemas-chave que o município de Alvito terá que gerir no futuro próximo.

O conteúdo dos debates realçou a centralidade da Escola neste processo. Questões como os tempos, e os espaços de partilha dos alunos nos períodos não letivos, por efeito da oferta de escola a tempo inteiro, revelaram-se como aspetos problemáticos, a requererem o aprofundamento da reflexão, tendo em vista o aportar de soluções que conciliem expectativas, necessidades e recursos e que permitam o envolvimento de todos os protagonistas: os alunos, as famílias, a escola e as associações locais.

As observações realizadas ao longo de todo o processo de construção do PEEMA e, em particular, nos fóruns, permitiram relevar a importância da proximidade e do interconhecimento dos atores locais para a agilização da resolução de imprevistos, mas que, no entanto, acrescentam dificuldades ao processo partilhado de planificação de atividades. Conscientes disso, diversos atores vêm/viram o PEEMA como uma oportunidade de trabalho em parceria, de forma organizada. Apesar de quase todos se conhecerem, concordam/concordaram que ainda havia muitos obstáculos à ação coletiva, sendo a construção e a implementação do PEEMA considerada uma oportunidade para a promoção da concertação coletiva. Para os participantes nos fóruns, e incentivados a expressar qual a grande mais valia do processo, destacam a metodologia de trabalho desenvolvida na medida em que permitiu o trabalho conjunto, a concertação, a planificação e a visão de conjunto dos recursos locais para promoção da dinâmica educativa municipal.

Dado o processo de partilha conseguido, desde o diagnóstico até ao plano de ação, devidamente contratualizado publicamente com todos, foi fácil identificar as metas estruturantes que todos se comprometem a tentar alcançar até 2021, a saber: 
Tabela 3 Metas assumidas no PEEMA para 2021

\begin{tabular}{|c|c|}
\hline Indicador & Meta em 2021 \\
\hline Taxa de analfabetismo & Diminuir 4\% \\
\hline $\begin{array}{l}\text { Proporção da população residente com pelo menos o } 3 .{ }^{\circ} \text { ciclo do Ensino } \\
\text { Básico Completo }\end{array}$ & Aumentar $7 \%$ \\
\hline Proporção da população residente com pelo menos o Ensino Secundário & Aumentar 3\% \\
\hline $\begin{array}{l}\text { Proporção da população residente, com idades compreendidas entre } \\
\text { os } 30 \text { e } 34 \text { anos, com ensino superior completo }\end{array}$ & Aumentar $5 \%$ \\
\hline Taxa de sucesso escolar (2.ำ ciclo e $3 .^{\circ}$ ciclo do Ensino Básico) & Aumentar $1,5 \%$ \\
\hline $\begin{array}{l}\text { Taxa de transição de ciclos (1.ำ ciclo, } 2 .^{\circ} \text { ciclo, } 3 .^{\circ} \text { ciclo do Ensino Básico } \\
\text { e Ensino Secundário) }\end{array}$ & Aumentar $1,5 \%$ \\
\hline $\begin{array}{l}\text { Taxa de abandono escolar (Proporção da população residente com idade } \\
\text { entre } 10 \text { e } 15 \text { anos que abandonou a escola sem concluir o } 9.0 \text { ano) }\end{array}$ & Diminuir $1 \%$ \\
\hline Número de jovens que instalam novas empresas em Alvito & Pelo menos 4 \\
\hline Número de alunos a frequentar a EPA & Aumentar $10 \%$ \\
\hline Nível de qualificação escolar e/ou profissional de adultos & Aumentar 10 adultos/por ano \\
\hline $\begin{array}{l}\text { Número de participantes do género masculino a frequentar a Universidade } \\
\text { Sénior }\end{array}$ & Aumentar $15 \%$ \\
\hline
\end{tabular}

Fonte: Saúde, Lopes e Machado (2017).

\section{Considerações finais}

As características, a metodologia e os resultados já alcançados consubstanciam o PEEMA como um importante instrumento de regulação da política educativa local, bem como, testemunho de um processo de (re)distribuição de responsabilidades entre os vários atores, com efetivos impactos na tomada de decisão política. Consideramos, também, que este processo assume contornos de um verdadeiro "laboratório vivo", e experimental, de como num território tão pequeno e fragilizado, pelos principais indicadores socioeconómicos típicos dos territórios de baixa densidade, pode ser partilhada a construção e a gestão de um instrumento de política pública. Embora em Portugal, o papel do Estado possa ainda ser caracterizado como centralista, uniformizador e demasiado afastado das reais necessidades e capacidades locais, em diversos domínios da sua atuação, há, no entanto, "espaços legislativos" que podem e devem ser utilizados pelos atores locais/regionais para construir e consolidar os seus poderes eáreas de intervenção. No domínio da Educação o planeamento e a gestão local justificam-se, desde que devidamente sustentados pela ação partilhada e participada por todos os atores que não só a escola, tal como a corroborada nos pressupostos de conceção dos Planos Estratégicos Educativos Municipais. 


\section{Notas}

1 Com autorização prévia de todos os participantes.

2 Para maior detalhe consultar Saúde, Lopes, e Machado (2016).

3 Ao longo da análise da série de nascimentos observados, entre 2001 e 2014, na população residente em Alvito, observam-se momentos intercalados de valores substancialmente mais elevados, apresentamos alguns exemplos mais significativos: 2006, $2008 \mathrm{e}$ 2013, onde face aos anos anteriores houve, respetivamente, um aumento de mais $26 \%$; mais 29\% e, em 2013 face a 2012, de mais 81\%. Esta situação vai ter impacto em determinados momentos letivos. Fonte: Saúde, Lopes, e Machado (2016).

4 No 3. ${ }^{\circ}$ ciclo do EB, ensino regular, as taxas de retenção e desistência baixaram de $21,4 \%$ (2013/14) para 13,5\% (2014/15).

5 Ver para o efeito a apresentação de informação na parte 1.3.3.1. Evolução da frequência escolar no ensino regular e profissional, em concreto no que se refere ao ensino secundário profissional. Fonte: DGEEC/MEC (2013).

Por decisão pessoal, as autoras do texto escrevem segundo o novo acordo ortográfico.

\section{Referências}

Almeida, V. (2014). Projetos educativos municipais e promoção do sucesso educativo. In J. Machado e J. M. Alves (Eds.), Município, território e educação: A administração local da educação, e da formação (pp. 25-31). Porto: Universidade Católica Editora. Disponível em http:/ /www.uceditora.ucp.pt/resources/Documentos/UCEditora/ PDF\%20Livros/Porto/Municipio\%20Territorio\%20Educa\%C3\%A7ao.pdf

Azevedo, J. (2015). Descentralização administrativa e autonomia das escolas. 2015: O ano em que se dá mais um passo em frente?. Atas do I Seminário Internacional Educação, territórios e desenvolvimento humano, Porto, Vol. I, 90-106. Disponível em http://repositorio.ucp.pt/bitstream/10400.14/18831/3/ Descentraliza\%C3\%A7\% C3\%A3o\%20administrativa\%20e\%20autonomia\%20das\%20escolas.\%202015.PDF

Barroso. (2013). A emergência do local e os novos modos de regulação das políticas educativas. Educação, Temas \& Problemas, (12-13), 13-25. Disponível em http://www.revistas.uevora.pt/index.php/educacao/article/viewFile/11/5

Cordeiro, A., Alcoforado, L., e Ferreira, A. (2014). Projeto educativo local. Um processo associado a estratégias de desenvolvimento integrado e sustentável. Cadernos de Geografia, (30/31), 305-315. Disponível em http://www.uc.pt/fluc/depgeo/ Cadernos_Geografia/Numeros_publicados/CadGeo30_31/Eixo3_6

Direção Geral de Estatísticas de Educação e Ciência (DGEEC/MEC). (2013). Modelo de previsão do número de alunos em Portugal - Impacto do alargamento da escolaridade obrigatório. Disponível em: http:/ / www.dgeec.mec.pt/ np4/64/\%7B\$clientServletPath\%7D/?newsId=65\&fileName=ArtigoPrevis_oAlun os_Portugal_final_0609.pdf 
Fernandes, A. (1994). Educação e poder local. Actas do Seminário Educação, comunidade e poder local, Lisboa, 45-64. Disponível em http://www.cnedu.pt /content/edicoes/seminarios_e_coloquios/educacao-poder-local.pdf

Formosinho, J., e Machado, J. (2013). A regulação da educação em Portugal - Do Estado Novo à democracia. Educação, Temas \& Problemas, (12-13), 27-40. Disponível em http://www.revistas.uevora.pt/index.php/educacao/article/viewFile/12/6

Guerra, I. C. (2000). Fundamentos e processos de uma sociologia de acção. Estoril: Principia.

Justino, D. (2012). Descentralização: Políticas e dinâmicas escolares em contextos municipais. Encontro Internacional História dos municípios na educação e na cultura: incertezas de ontem, desafios de hoje, Lisboa. Disponível em http:/ / sociologia.davidjustino.com/wp-content/uploads/2013/05/Descentraliza $\%$ C3\% A7\%C3\% A3o-Pol\%C3\%ADticas-e-Din\%C3\%A2micas-Escolares-em-Context os-Municipais.pdf

Nóvoa, A. (2009). Educação 2021: para uma história do futuro. Revista Iberoamericana de Educación, (49), 1-18. Disponível em http://rieoei.org/rie49a07_por.pdf

Pinhal, J. (2014). Regulação da educação: Os municípios e o Estado. In J. Machado, e J. M. Alves (Eds.), Município, território e educação: A administração local da educação e da formação (pp. 8-14). Disponível em http://www.uceditora.ucp.pt/resources/ Documentos/UCEditora/PDF\%20Livros/Porto/Municipio\%20Territorio\%20Educ a\% C3\%A7ao.pdf

Saúde, S., Lopes, S., e Machado, F. (2016). Carta Educativa Municipal de Alvito - 2016. Alvito: Câmara Municipal de Alvito. Disponível em http://cms.cm-alvito.pt/ /upload_files/client_id_1/website_id_1/A_Atividade_Municipal/Educacao/doc /Carta \%20Educativa.pdf

Saúde, S., Lopes, S., e Machado, F. (2017). Plano Estratégico Educativo Municipal de Alvito. Alvito: Câmara Municipal de Alvito.

\section{Legislação consultada}

Decreto-lei n ${ }^{\circ}$ 30/2015. (2015). Estabelece o regime de delegação de competências nos municípios e entidades intermunicipais no domínio de funções sociais. Diário da República I Série $N^{o} 30$ (12/02/15), 838-841.

Lei $n^{\circ} 75 / 2013$. (2013). Estabelece o regime jurídico das autarquias locais, aprova o estatuto das entidades intermunicipais, estabelece o regime jurídico da transferência de competências do Estado para as autarquias locais e para as entidades intermunicipais e aprova o regime jurídico do associativismo autárquico. Diário da República I Série. No 176 (12/09/2013), 5688-5724. 
Filomena Machado. Técnica Superior estagiária do Instituto Politécnico de Beja e Investigadora do Laboratório de Animação Territorial, IPBeja.

Sandra Saúde. Professora Adjunta do Instituto Politécnico de Beja e Investigadora Integrada do CICS.NOVA - Centro Interdisciplinar de Ciências Sociais e do Laboratório de Animação Territorial, IPBeja.

Sandra Lopes. Professora Adjunta do Instituto Politécnico de Beja e Investigadora Integrada do CICS.NOVA - Centro Interdisciplinar de Ciências Sociais e do Laboratório de Animação Territorial, IPBeja.

Data de submissão: 29/05/2017 | Data de aceitação: 25/09/2017 